\title{
THEORY, MEASUREMENT, POLICY AND POLITICS: AGRICULTURAL R\&D \& PRODUCTIVITY IN THREE COUNTRIES
}

\author{
Colin Thirtle, Imperial College London \\ University of Pretoria \\ University of Stellenbosch
}

\section{INTRODUCTION}

If it's not worth doing, it's not worth doing well. J W Tukey

It is a great honour to present the Simon Brand memorial lecture on the $50^{\text {th }}$ anniversary of the founding of LEVSA. The theme of this conference is AEASA 1961-2011: a foundation for the next 50 years. But does looking back help? Robert Mundell (Nobel prize, 1999) told our class at Columbia University that the past and the future are symmetric; we know equally little about either. The way history is now being rewritten, I finally understand what he meant. The undefined acronyms can serve a purpose. After reading a useful paper by Kirsten and Liebenberg on R\&D expenditures in South Africa, I pointed out they needed a table of acronyms. In response I got an email saying that these were left undefined in order to conceal the true extent of the tragedy.

I have been involved in South Africa for 20 years, but I am not South African and I have never taken a course in agricultural economics. As an outsider looking in I have no intention of telling you your business. We have always left that to the World Bank. This address tries to put our discipline in methodological perspective. It assesses how we have fared in my own areas of production and technology, looking at past developments, with emphasis on how we try to balance theory, measurement, relevance, policy and politics. It considers our profession's functions and how well we have succeeded in the US, the UK and South Africa. Hopefully, the result is an internationalised background to put the specifically agricultural and South African papers that follow into a broader context.

The next section begins with epistemology, explaining why observation, explanation, prediction and testability in economics are difficult. Section three reviews progress in applied production economics, growth and technological change with an emphasis on the considerable contribution of agricultural economists. Section four is on my personal experience of the profession's effectiveness the USA, the UK and South Africa, which suggests with 20/20 hindsight that we have done far better at earning our keep in South Africa than in the UK. Section five concludes with predictions and suggestions for the future.

\section{EXPLANATION AND REFUTATION: EPISTIMOLOGY IN ECONOMICS}

Nature and Nature's laws lay hid by night:

God said, let Newton be! And all was light.

Alexander Pope's proposed epitaph for Isaac Newton, who died in 1727.

\section{Scientific method}

If we follow the logical positivists and Popper (1959), the demarcation criterion between science and non-science is testability, or the ability to confront refutable hypotheses with empirical 
evidence. All swans are white is a refutable statement and is indeed false, but it lacks explanatory power. Thus, 'swan-ness causes whiteness' could be called a hypothesis, if a rather silly one. Newton is justly famous for providing the general theory of gravitation, which explained the planetary motions observed by Tycho Brahe and Johannes Kepler. His theory also predicted the planetary orbits and predictive power has become one measure of success in theorising. ${ }^{1}$ Thus, "the prediction of the existence of the planet Neptune was the consecration of the prophetic power inherent in the Newtonian vision." (Pregogine and Stengers, 1985)

Observation, explanation and prediction, with testability sounds good, but as Lakatos (1970) stresses, there is usually no body of proven knowledge that can be called empirical evidence, with which to confront a hypothesis. ${ }^{2}$ Most evidence is itself based on theory that may be false. Thus, when Flamsteed, the Astronomer Royal, informed Newton that his theory of gravitation was disproven as the planets did not follow the predicted orbits, Newton replied that it was Flamsteed's observations that were wrong because they did not allow for light rays being refracted by the earth's atmosphere. Lakatos uses Newton's work as an example of positive problem shifts in a scientific research programme (SRP), as opposed to degenerative shifts when a programme is in decline. But all was not entirely well, as despite its huge successes, Newton's theory did not explain the orbit of Mercury and Prigogine and Stengers (1985) quote Heidegger, who argued that by his time science had ceased to be experimental as it did not question nature but set up experiments to ask how nature followed the schemes preconceived by science. So even in celestial mechanics, theories are imperfect, refutability is difficult and a theory is never rejected until there is another to replace it. But can we measure, explain, predict and refute in economics, where the difficulties seem greater?

\section{Epistemology in economics}

One hazard of our profession is that we mix with agriculturalists. A professor of pig science told me that economics is not a proper science because it is inexact, a common view amongst scientists, but misguided. The valid distinction is between laboratory sciences and the rest, such as agronomy, where measurement requires statistical methods. However, in agronomy, experiments can be repeated, but in social science experiments occur only once and we never see the counter-factual history to allow us to isolate the effects of policy changes. ${ }^{3}$ Worse still, whereas atoms behave the same each time an experiment is repeated, our subjects are humans and they learn from past mistakes and behave differently. Finally, Newton never had to deal with policy, which we will see is an important difference. Thus, Niels Bohr was not joking when he said he wanted to be an economist but it was too difficult, so he settled for nuclear physics.

\section{Observation and measurement}

The importance of observation and measurement was accepted by much of the profession by the 1920s while theory was still frowned upon, especially if it involved mathematics, and econometrics was just emerging. Thus, Wesley Clair Mitchell and others at the National Bureau of Economic Research (NBER) were developing systematic economic data while even in England where demand theory was highly regarded, Fox (1986) says few thought that Jevons' dream of statistical demand curves would ever be realised. The NBER's regard for measurement

\footnotetext{
${ }^{1}$ Newton developed the calculus, used it to produce the general theory of gravitation, proved experimentally that white light is composed of all the colours of the spectrum and interpreted the Book of Revelations in a period of about 18 months, when he was at home alone because the university was closed due to the plague. What policy advice would you draw from this observation?

${ }^{2}$ Popper (1963) goes so far as to say there is no such thing as objective knowledge and even if we saw it we would not recognise it.

${ }^{3}$ Although history does not do reruns, we can actually repeat similar experiments many times. Indeed, far too many very similar papers have been written in areas like adoption of techniques.
} 
is well founded and history shows there is no doubt that societies with effective accounting systems have progressed better than those without. The collapse of the USSR owes a lot to Marxist accounting systems could not separate success and failure, giving policy makers no guidance and Lipton (1989) argues that it is the abysmal quality of data in Sub-Saharan African agriculture that has inhibited many attempts at agricultural development.

\section{Theory}

However, Koopmans (1952) critique of Burns and Mitchell's studies of the business cycle, argued that empiricism without explanation and prediction cannot guide economic policies. Theory makes order out of the chaos of a complex and ill-defined reality. Abstracting from reality, theory identifies the most important variables and makes problems tractable, but should this not be done econometrically? If the theory precedes any testing, there is the danger that we find only what we are looking for, having omitted other key variables that might have changed our preconceived answer. Indeed, science is supposedly inductive and the observation (the egg), must precede the hypothesis (chicken). But how were the observations chosen? There has to have been an earlier, inferior hypothesis, which must at some point be from personal experience, although introspection is unscientific. This leads to the story recounted by Amartya Sen, of the two behavioralists who meet in the street and one says to the other, "Hi, I see you are fine today, how am I?"

\section{Refutability and Politics?}

So, can we confront a hypothesis with empirical observations and either corroborate it or reject it? If theory is a set of logical deductions and there are no mistakes, it is really the assumptions we are testing. In macroeconomics there are testable hypotheses, but agricultural economics is very largely micro based. Caldwell (1982) says that the most basic assumption of economics is rationality, but does not think it is refutable. ${ }^{4}$ The assumptions in microeconomics are often simplifications, such as static profit maximisation in the theory of the firm. ${ }^{5}$ This can be innocuous in commercial agriculture, but is clearly quite wrong for modelling the behaviour of risk-averse semi-subsistence farmers so much is left to our discretion. It seems that microeconomic theory has become a logical framework used more to put upper and lower bounds on our estimates rather than a set of testable hypotheses.

Staying within my comfort zone of production theory, we alternatively assume that the objective function is output maximisation subject to input constraints and fixed technology, or cost minimisation, or profit maximisation. In the first case, the theory leads to logical constraints on the empirical results. The elasticity of output with respect to each input has to be between zero and unity, or the farmer is operating outside of the economically rational region of the production function (Tangri, 1966) ${ }^{6}$. This is not a matter of strong prior beliefs, such as the notion that competition increases efficiency: it is rather more a logical requirement, which subject to the assumptions has to be true.

Blaug (1980) argues that economics cannot fit into Lakatos's methodology of SRP, because it is a policy science. Lakatos (1970, p92) writes, "Belief may be an unavoidable biological weakness to be kept under the control of criticism: but commitment is for Popper an outright crime". But agricultural economists frequently addresses matters on which government must

\footnotetext{
${ }^{4}$ How do we represent rationality? The rationality assumption in consumer theory is transitivity, which looks like simple logic.

${ }^{5}$ We know this is not really true and Herbert Simon got the 1978 Nobel Prize for examining satisficing behaviour

${ }^{6}$ When counting up the contributions of agricultural economists we can include Tangri.
} 
make policy decisions, so that economic doctrines are simultaneously SRPs in the manner of Lakatos and political action programmes (PAP)s. The two are not often in the progressive phase at the same time. Indeed, Blaug (1980) thinks perhaps only in the case of Keynesian economics following World War II.

It is almost impossible to preserve a proper scientific detachment in such circumstances. ${ }^{7}$ Twice in my career, starting when I was still a student, I have been advised not to tell the funding agency the whole truth, as it was likely to lead to policies that could cause damage. On a third occasion, a co-author withdrew his name from a good publication because our results were at odds with his policy advice and he did not want to be inconsistent. So, there is a real sense in which scientific objectivity is at odds with relevance and policy advice. These situations also raise ethical issues: do we have any right to decide what to report?

Blaug (1980) thinks that the battle for falsificationism in economics has been won, but puts this in perspective by noting (p125-6) that we tend to "play tennis with the net down...instead of trying to refute testable predictions, modern economists all too frequently are satisfied to demonstrate that the real world conforms to their predictions". 8 He notes the weakness of applied econometrics and says that we need to try harder: the next section will show we have tried to raise the net a bit. Caldwell (1982) similarly pursues the goal of falsificationism but ends with a good account of why it is so hard to achieve. His case stresses the numerous initial conditions, some of which are uncheckable: the absence of falsifiable general laws: the lack of clear fit between theory and data: and the fact that we test models, not theory.

The last point is attributable to Boland (1977), who argues that a wide variety of models can represent any underlying theory, so that falsification of a theory is not possible. ${ }^{9}$ Many would say that we also test the data rather than the theory, which is what Lakatos (1970) and others suggest has usually been the case in the physical sciences too. But we do need to test the data and the models rather than the simple logic of micro theory. Leontief and later Griliches (1994) both stressed better data as our greatest need, but increasingly, understanding what the data have to say is also recognised as a problem.

The next section considers if the SRP in agricultural production economics, growth and technology has been progressive. But I think international comparisons will show that the PAP has to be considered too and the stronger the PAP, the tighter the priors in the SRP and the lower the likelihood of refutation.

\section{APPLIED PRODUCTION ECONOMICS, GROWTH, R\&D AND TECHNOLOGY}

\section{The great tragedy of science: when a beautiful hypothesis is slain by an ugly fact} T H Huxley

\section{When agricultural economics led the world}

Perhaps the only time that agricultural economists led the world was in the development of applied econometrics in the 1920s (Fox, 1986). The Bureau of Agricultural Economics (BAE) in Washington DC was exceptional. In theory, Mordecai Ezekiel was constructing dynamic cobweb

\footnotetext{
${ }^{7}$ Kuhn (1970) takes a totally different position. For him the transition from criticism to commitment is where progress and normal science begins.

${ }^{8}$ See Heidegger on page two.

${ }^{9}$ Caldwell (1982) explains Boland's view that we can never find a true theory, because we would not recognise it even when we find the truth. This is the Popper position, of footnote two above, applied to economics.
} 
models while the economists stuck with comparative statics. In econometrics the estimates of the supply and demand for agricultural products advanced the subject enormously, but the high point was perhaps Sewell Wright's work, in which he has unobservable dependent and independent variables but still solves the system by a method he called path analysis. Goldberger's (1974) review states this was not bettered for fifty years.

\section{Developments in production economics}

Agricultural economists continued to contribute later. The first microeconomic production function was agricultural (Tintner, 1944) and the translog was used by Heady and Dillon (1962) long before it was popularised by Christensen, Jorgensen and Lau (1973). Whereas the Cobb Douglas was static and imposed restrictions on the data, flexible functional forms such as the translog do not impose linearity and allow both estimation of parameters like elasticities of substitution and disequilibria.

The production function can be estimated as a single equation, but frequently imposing more structure by fitting a system of simultaneous equations gives better estimates. Thus, the second major advance is the use of duality which introduces the full range of economic variables into models consisting of the output supply and input demand functions, so we can now deal with several outputs.

The stochastic production frontier approach is another major advance in production as it ranks all farms relative to the best practice frontier, rather than simple being an average response function, like OLS regression. This is done by decomposing the error term into a one-sided systematic component which is deemed to be efficiency and a random residual. Thus, the deviation of each observation from the frontier is used as the measure of the level of efficiency.

\section{The computer and applied economics}

The most important development in economics has been the advent of cheap and powerful computing, which has transformed most branches of the subject from elegant theoretical games to ugly but more relevant empirical estimation. ${ }^{10}$ When explaining price indices I used to tell students that the price of a labour intensive haircut with no technological progress would soon be more that the price of a computer. I was wrong: it happened some years ago. In 1982 an IBM PC cost about $\$ 3000$. By 2002 the cost of the same amount of computing power embodied in the latest Dell PC was less than \$1 (data from Nordhaus, 2002). The development of hardware has been matched by the rapid profusion of specialised software, which has made quite complex estimation available to all.

The developments in time series econometrics pioneered by Hendry, Sims and Leamer and explained by Townsend $(1997,1998)$ have improved testability. Economic time series are now tested to ensure that the exogenous variables really are exogenous, that they have the characteristics required to explain the dependent variables (stochastic or trended, order of integration), that the series are cointegrated and the directions of causality are also established. It is now normal to look for structural breaks, to model the effects of exogenous shocks by using impulse response functions and to allow disequilibria with error correction models. It is the discontinuities that tend to make our advice necessary. My own view is that the new techniques and software have been extremely useful in improving our estimates, but they have been used to test the data and refine the models that are fitted to it, not to try and refute any aspects of neoclassical theory.

\footnotetext{
${ }^{10}$ There are two things you are better off not watching in the making: sausages and econometric estimates. Attributed to Edward Leamer
} 


\section{Technology and economic growth}

Neoclassical economics began with the marginalists and is modelled on classical mechanics, making it somewhat obsessed with equilibrium. In the area of growth and its explanatory factors such as technological change, it is easy to see why many economists were disenchanted with neoclassical theory and also to show how the computer and the upsurge of empirical economics have improved matters. Schumpeter has the best critical lines on the matter, saying that the marginalists were studying cost cutting amongst harness makers, when the proper object of inquiry should be the emergence of the automobile industry, which was about to render harness making a defunct economic activity. His other gem is the observation that no matter how many marginal stage coaches you might add, you will never get a railroad thereby. ${ }^{11}$ In classical mechanics, the natural state of the pendulum is at rest and this makes neoclassical economics a poor starting point for analysing economic change. This and other factors have led to neoSchumpeterian versions of the economics of technology and to Nelson and Winter's (1982) evolutionary theory. These developments may prove to be a good direction, but neoclassical economics should not be dismissed, as it has reinstated growth and technology.

Solow's (1957) classic empirical paper on economic growth showed that capital accumulation explained only 12.5 percent of US industrial growth. The residual had $87.5 \%$ of the variance to explain, so technology became a hot topic. So much so that Hicks, in his 1973 Nobel lecture, called technology "the mainspring of economic growth". Thus, technology was put at centre stage, but the theoretical growth literature ground to a halt as it departed from reality and policy relevance. If the steady state is not going to be reached in our lifetimes, its characteristics are not going to interest policy makers.

The computer brought growth back to life with endogenous growth models that showed the policy makers that the driving forces in the growth process were the inputs with major public good characteristics. R\&D produces new technology which is non-rival in use, so all producers can adopt it. Education similarly has large positive spillovers and these two factors are dominant. This literature, some associated with Bill Easterly's group at the World Bank attracted attention on a scale never achieved by Hayami and Ruttan (1985), something that rankled with Vern Ruttan for years, as he considered that we agricultural economists had all been studying endogenous growth for many years.

\section{Productivity growth, technology and $R \& D$ in agriculture}

In agricultural economics, the pursuit of the causes of growth was always more empirical and closer to reality and Evenson (2000) leaves no doubt that it is the application of modern science to agriculture that has transformed the sector. The literature on agricultural development, at least since Hayami and Ruttan's (1985, first edition 1971) seminal contribution, stresses the roles of yield growth that results from the application of science and the mechanical revolution that followed Benz's invention of the internal combustion engine. These developments created the cheap modern land substitutes that induced the biological innovations that transformed yields, allowing the relative price of food to decline for decades, despite the relative fixity of land.

Thus, Alston et al. (2010) show that for the US, from 1911 to 2002, yields increased by a factor of 4.4, labour productivity increased by a factor of 15.3 and TFP by a factor of 4.1. Similarly, by the early 1980s in the UK, the labour input required to produce crops like potatoes, sugar beet, wheat and barley was only one tenth the 1930 level and, over the same period, wheat yields increased by a factor of three (Grigg, 1989). From the Second World War to the early 1980s,

\footnotetext{
${ }^{11}$ Quoted by Rosenberg (1982).
} 
tractor horsepower increased more than ten-fold and nitrogen fertilizer application grew by a factor of six (Holderness, 1985).

These achievements required massive and sustained expenditures on R\&D. The US expenditures are recorded by Huffman and Evenson (1992) and those for the UK by Thirtle et al. (1997). Much of the plant improvements were the work of the public sector, while mechanical innovations have been mostly attributable to private R\&D. The diffusion of both biological and mechanical innovations takes many years, so there is a long lag between the R\&D expenditures and the productivity gains at the farm level.

\section{Measuring and explaining total factor productivity}

The ratio of aggregate output to all inputs combined, all in physical terms, gives a measure of total factor productivity (TFP). Thus, all that is required is to keep on aggregating until there is only one output and only one input. The first TFP index was for US agriculture and was constructed by two United States Department of Agriculture (USDA) employees, Barton and Cooper (1948). This achievement was the measurement stage, but in the 1950s and 60s our subject entered the explanation phase as technological change began to be modelled. Tintner (1952) first included a time trend in the production function to take account of changes over time and avoid estimation error. Then Schultz (1953) and Griliches (1958) estimated the returns to public agricultural R\&D. Griliches (1964) combined the two developments by including R\&D in the production function and by the later 1960s, Evenson began a life long commitment to this area of study. By the 1970s and 80s he and others were routinely measuring TFP and then explaining the their series with $R \& D$, which generated the new technology at the research stations, extension expenditures that took them to the farmers and farmer education, as more educated farmers were thought to be better at screening and adapting technologies.

The long lags between R\&D and TFP were first modelled following as second degree polynomials (inverted $U$ shapes) of some 12 years duration, on the advice of the agricultural researchers. For the UK, the lag seems to be about 27 years (Thirtle et al., 2008), for the US Pardey and Craig (1989) found lags of between 20 and 40 years and Huffman and Evenson (1992) calculated R\&D stocks using a trapezoid with a 35 year lag. There is also good evidence that spillovers between research jurisdictions are as important as direct benefits within countries (Schimmelpfennig and Thirtle, 1999). The relationship between public and private R\&D has been less studied, but it seems likely that the two are complements rather than substitutes (Thirtle et al., 2004). The relationship between basic and applied research was pioneered by Evenson, Waggoner and Ruttan (1979) and the lags between basic and applied research and diffusion are studied in Thirtle et al. (1998).

All of these developments emanated from agricultural economics, and I think we can claim a progressive SRP. Add too Nerlove's (1958) study of supply response which popularised the partial adjustment model and much of the work on risk and uncertainty followed from work by Just and Pope. Not bad going for a small subset of the economics profession, but note that almost all is from the USA and exceptions like myself studied and worked there. 


\section{A TALE OF THREE COUNTRIES: DIFFERENCES IN R\&D AND PRODUCTIVITY}

Far better an approximate answer to the right question, than the exact answer to the wrong question. JW Tukey

I know it is unscientific to rely on one's personal experience, but I have no other. I have lived and worked in the USA, the UK and South Africa. This section is intended to show how successful agricultural economics has been in these three countries, in my own area of R\&D, technology and productivity growth. All three faced major changes and challenges and we will see how well they coped and suggest why.

\section{The USA: how to get it right}

Ronald Regan's public sector cutbacks began with the disbanding of the USDA's Science and Education Administration in 1982, which was a warning shot for the agricultural research community. Agricultural economics in the USA clearly has more resources than most countries can afford. The Economic Research Service (ERS) is my most long-standing academic affiliation. When I taught there in the 1990s the production and technology branch had over 30 research staff, or more than twice as many as the entire Agricultural Economics department at Reading, which was the largest in the UK.

Having an active group of researchers working in the same organisation as the data collectors is another important feature of the USDA, as the data branch gets told what is needed by researchers. The USDA also employs a large number of physical scientists, so the agricultural economists are in contact with science rather than being isolated. This articulation continues, with strong links and funding from USDA to the Land Grant Colleges, which again mix social and physical scientists. Both run extension services that complete the chain from the laboratory to the farm. And, as the last section showed, the US profession had been measuring TFP since 1948 and explaining the impact of R\&D at least since 1953.

With thirty years of experience and good linkages across disciplines, the agricultural research community had a PAP, with the evidence needed already in place. Vernon Ruttan became the first agricultural economist to be awarded the Alexander von Humbolt prize for services to American agriculture. The service was defending the sectors' budgets when the Regan administration began wielding the axe. This was not entirely successful as Figure 1 shows, but the cuts where staved off for some years and were minimised when they did occur in the 1990s, by which time private R\&D had overtaken public, so that the sector is still enjoying productivity growth.

This combination of appropriate institutions and organisations that worked coherently to create the intellectual capital needed from 1982 did not just happen, but the payoff is shown in Figure 2, where TFP growth has continued at around 1.6\% per annum throughout this difficult period. The publication this is taken from shows that one percent per annum growth in R\&D funding is needed to maintain the TFP growth rate. Holding nominal R\&D expenditures constant would result in TFP growth falling to about $0.65 \%$ per annum. Coming from a public sector institution, this shows how strong the PAP is in the USA. It may not be good science, but it has surely been politically effective. 
Figure 1: Public, Private and Total Agricultural R\&D in the USA

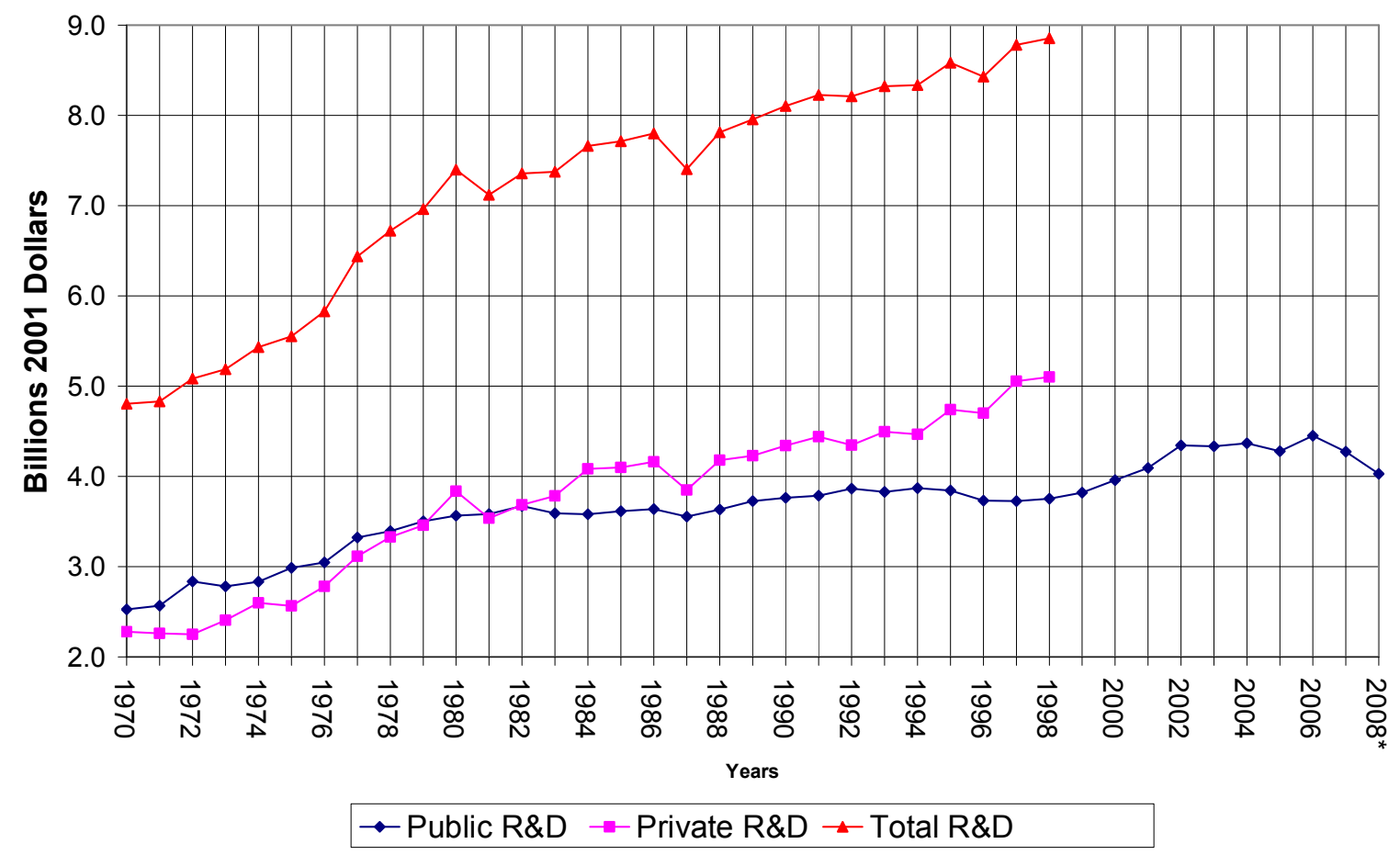

Source: USDA/ERS website (2012)

Figure 2: Agricultural Output, Input and TFP Growth in the USA

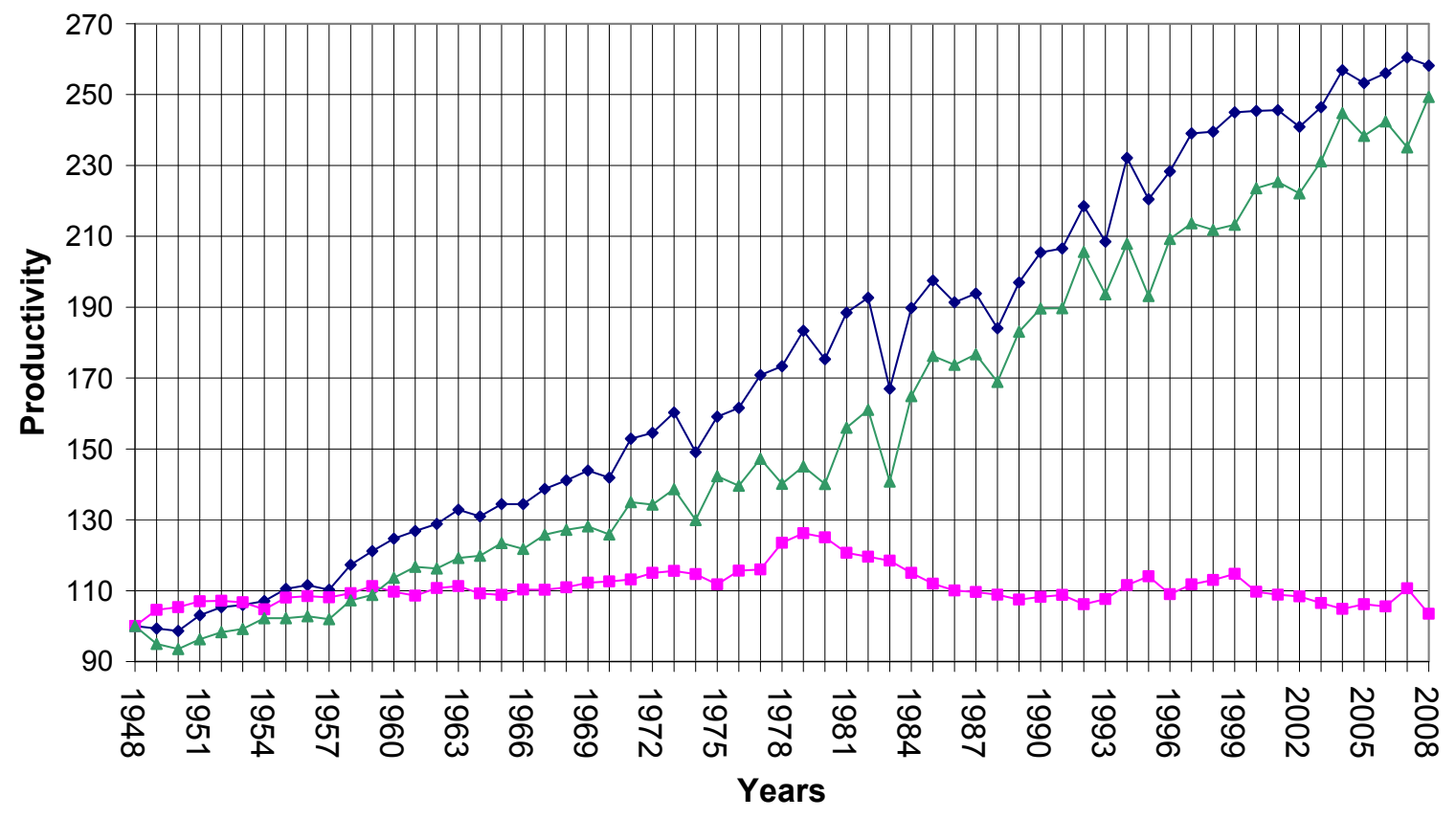

$\rightarrow$ Output $\rightarrow-$ Inputs $\rightarrow$ TFP

Source: USDA/ERS website (2012)

The UK: how to get it wrong

From 1982 Mrs Thatcher began cutting agricultural R\&D substantially, as Figure 3 shows. The Agricultural and Food Research Council (AFRC) had minimal links to the agricultural economists 
and prior to the cuts the heads of all the research councils were called before a treasury committee. The AFRC representatives were asked how it was that their sector was less than $2 \%$ of GDP but used $10 \%$ of public funds. They had no answer. The correct response would be that the $2 \%$ is just behind the farm gate. If the input industries, processing and distribution (the food chain) is included it rises to above $10 \%$. Better still, food and drink, including eating out was over $20 \%$ of final demand.

Figure 3: Public Sector R\&D Expenditures in the UK

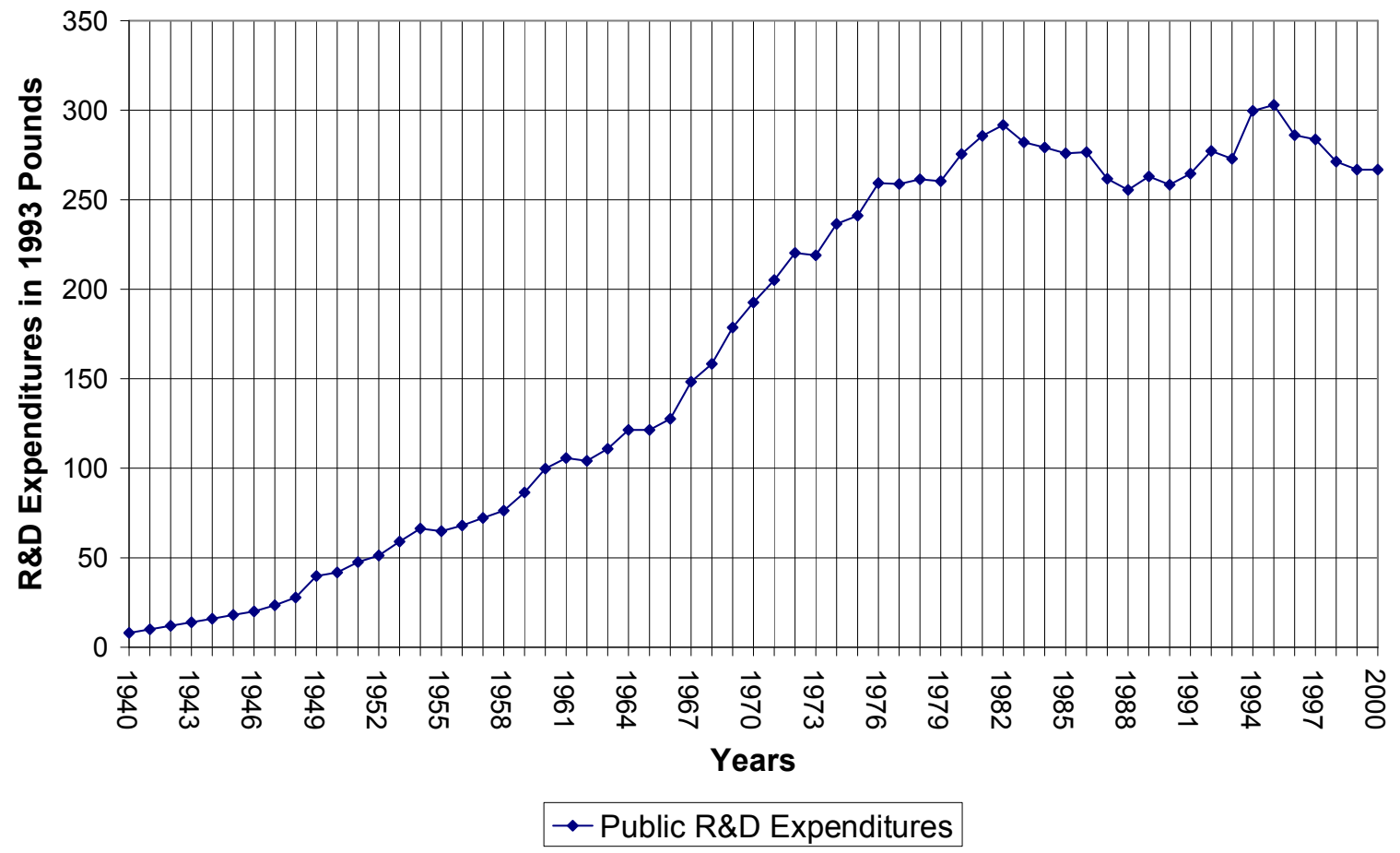

Source: Thirtle, Palladino and Piesse (1997)

The profession was not at all inclined to defend the R\&D budget. Instead, Wise (1986) argued that our techniques were inadequate and that more funding was not appropriate ${ }^{12}$. Motivation by these events, we produced estimates of the rate of return (ROR) to agricultural research in the UK (Thirtle and Bottomley, 1988), which were very high, but this was six years after the cuts and our paper was not well received. The AFRCs Animal Disease Laboratory at Pirbright was seriously cut. With no outbreaks of foot and mouth disease in years it was regarded as a fire brigade that had put out all the fires. Mad cow disease, foot and mouth, e coli and salmonella all followed, which led to more funding of animal health and food safety research, but this was ex-post.

Better defence required better data but the TFP data available to Thirtle and Bottomley (1992) was not adequate to establish the causality running from R\&D to TFP. By the late 1990s government attitude changed to one of freedom of information and collaboration with academia. We were then commissioned to review and update the Ministry's production statistics. We produced TFP accounts using the USDA methods devised by Eldon Ball. These series, from Thirtle et al. (2004) show that the effect of the R\&D cuts in the 1980 s seems to be a long period of zero growth in TFP, as Figure 4 shows. But what use is this to influencing policy, coming over 20 years after the event? The damage had long been done. Anything we do that is based on historical

\footnotetext{
${ }^{12}$ Bill Wise was a physicist who had worked for the AFRC. He had attended a meeting in the USA where he explained to the American agricultural economics profession that the AFRC had no need of economists.
} 
data has this defect. How long after the series has turned can annual fluctuations be distinguished from a turning point? ${ }^{13}$

\section{Figure 4: UK Agricultural TFP in Collaboration with MAFF}

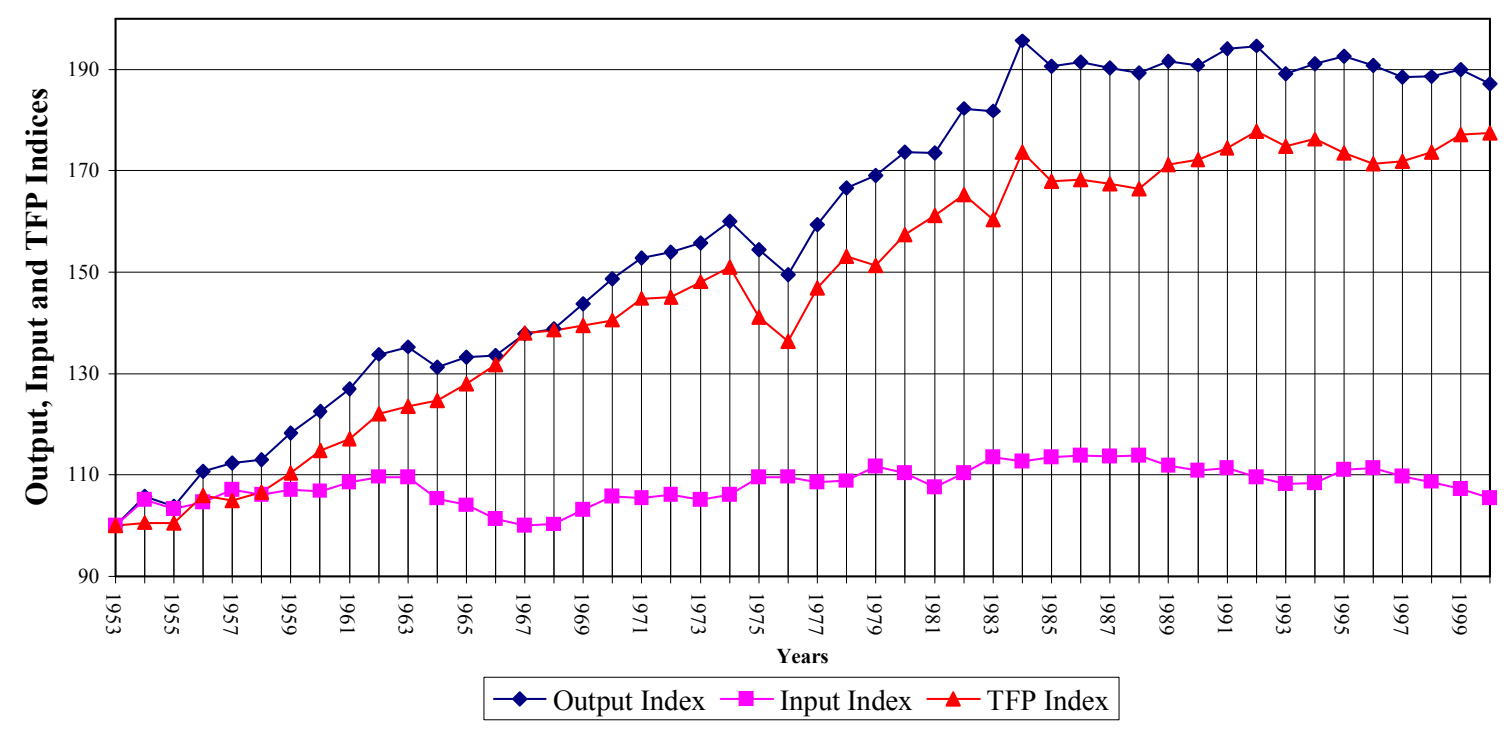

Source: Thirtle et al. (2004).

The cost of the cuts and lack of response are best judged by Figure 5, which shows what this means in terms of international competitiveness. Whereas the UK had the same productivity level as France in the early 1980s, by 2001 the gap was 37 points and the French were one third more productive than the UK. Denmark, the leading country was actually over $50 \%$ more productive and if data for Italy and Germany were available for recent years it is highly likely to show that they have by now overtaken the UK.

\footnotetext{
${ }^{13}$ This seems to be a common problem. Right up to the 2008 food price spike we were all telling the world that food prices had been falling since World War II. At a conference at Wye in 2008, Sarris had a slide showing that prices had actually stopped falling in the mid 1980s. I did simple econometric tests that confirmed this.
} 
Figure 5: TFPs for the Leading EU Countries and the UK

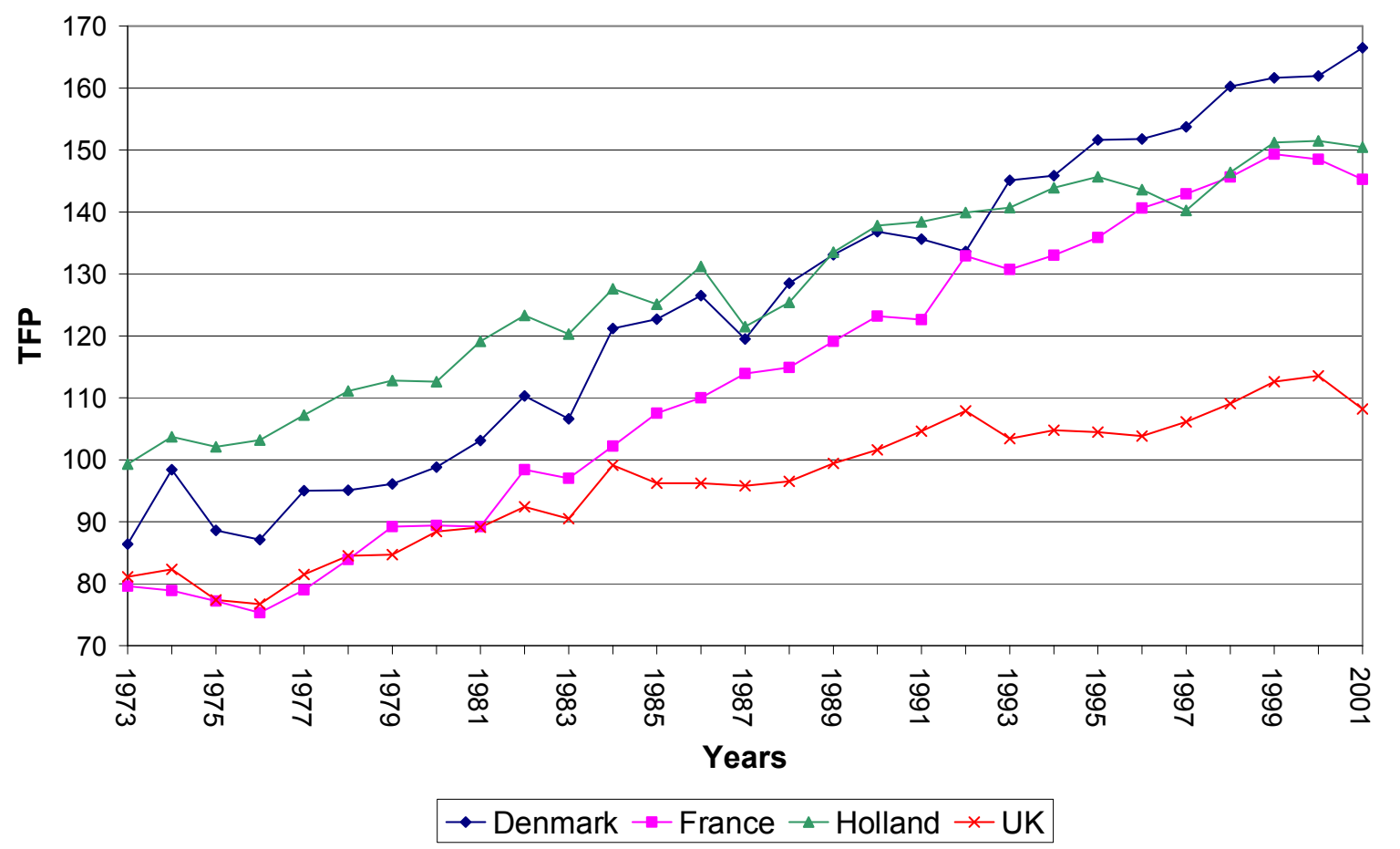

Source: Thirtle et al. (2004).

I suspect that many UK agricultural economists regarded the US PAP as unscientific, which PAPs are, but they seem to be a pretty good idea, when the alternatives are examined. The UK did not have a coherent agricultural research community in this difficult period and the links between disciplines still look weak and lacking in continuity. This seems like a problem in a world where multi-disciplinary research is becoming a requirement. The story is too little, too late and no articulation of the agricultural interest groups.

Our models of the rate of return, noted above, took a few tentative steps closer to reality by including spillovers between country jurisdictions, which for public R\&D proved to be at least as important as direct national effects. Thus, we began to tackle the globalisation of agricultural R\&D and technology, even finding some evidence of spillovers from the UK to South Africa. Even more to the point, with private expenditures now greater than public in the USA and UK, but with no expenditure data, we modelled private technology generation by including patent counts, registered by country of origin $i$, in country of use $\mathrm{j}$. So, we finally have convincing evidence of the importance of agricultural R\&D, but almost twenty years after the cuts. The UK looks a disaster, due to lack of data and research already on the shelf when the cuts started. By contrast, the US profession had what they needed to defend their position long before the Reagan administration started to look for savings.

A UK example of successful closer involvement is also in order, or I will give the impression that I am biased. Our work on the poverty impact of agricultural R\&D and productivity growth (Thirtle et al., 2002) was sadly not a result of our own brilliant choice of topics, but was conducted at the suggestion of the Department for International Development. Showing the relatively low cost of poverty reduction from agricultural productivity growth gave Bob Thompson, who was then head of rural development at the World Bank, some useful ammunition for defending his budget. I think we can claim to have paid for our keep, but we surely have not done it by refuting hypotheses. 
Maybe that is not the point in a policy science, where we have many functions and have to indulge in politics.

\section{Direct involvement in politics and policy in South Africa}

South Africa faced a huge change in the early 1990s with the advent of majority rule and the scrutiny of a World Bank team appraising agriculture. Your profession needed to show that it could deliver information and by the time the World Bank arrived there was a TFP for South Africa (Thirtle et al., 1993). The important point is that the information was in place before the event, not several years later. The policy advice here was that the labour saving bias was exacerbating rural unemployment, but I doubt that it could have been reversed. Indeed, since majority rule and the passage of minimum wage and workers right legislation, employment has fallen much faster.

Our estimates for South Africa were based on expenditure series for R\&D and extension that were presented to us by the National Department of Agriculture. Within the rate of return literature, we modelled the length and shape of the R\&D lag endogenously, letting the data determine both on the basis of econometric tests. Our results showed that the high returns to R\&D in South Africa relative to the UK and similar countries resulted from concentrating on adaptive R\&D. The lags are much shorter so there is less discounting, hence the higher returns. This information does have some pretty clear policy relevance, but the testing was not of neoclassical theory but of the characteristics of the data and the specification of the models.

The first study at a lower level of aggregation arose from being directly involved in politics and policy in the mid 1990s, when the ARC enlisted us to prepare their defence for a somewhat hostile review arranged by the UK Department for International Development. The ARC had talked to us and were aware that they had to show that their public funding was a socially beneficial investment with a good return to public funding. So, whereas all the rate of return studies mentioned above merely show that agricultural R\&D is a high payoff investment, in this case we did separate calculations for each of the 15 ARC institutes. This has far reaching policy implications, as the results could be used to determine the allocation of research resources between activities, such as fruit and wine, field crops and animal agriculture. Our results showed that in arable agriculture, only the ornamental flowers did poorly due to the long lags in R\&D. Deciduous fruit showed a return of around $100 \%$ per annum and field crops about $30 \%$ but for animal agriculture the return was an abysmal 0 to $5 \%$. Our theory says that resources should be reallocated until the rates of return are all equal, which would mean pouring the animal funding into fruit $R \& D$. The problem with stepping this close to the politics of research resource allocation immediately became apparent as the heads of the animal institutes approached the University of Pretoria wanting Johan van Zyl fired as Dean for masterminding this pernicious attack on their status, which was deemed to be wholly wrong and unscientific. So, the basic information was prepared in time for the review, but it took Townsend and Thirtle (2001) a long time to rectify the poor estimate for animals.

In doing this we did refute one false assumption in the rate of return literature, which is that with no R\&D TFP would be unchanged. In fact, in the sub tropical disease ecology of South Africa, without research on animal health to maintain the herds, there would be few animals left. The great rinderpest epidemics of the late $19^{\text {th }}$ century make this clear. As the health maintenance institutes were separate from those engaged in productivity enhancing $R \& D$, we could separate the funding and as we had data on animal deaths from disease as well as productivity, we were able to model the animals with two equations and show good rates of return to both activities. 
How successful were our efforts? The ARC did suffer budget cuts, as Figure 6 shows, but these seem to be from about 2000. The ARC has to face the hugely increased competition for funding that has followed majority rule and as Figure 7 shows, the productivity position is not secure, as growth seems to have ceased from about 1989 , or is it from the early $1990 \mathrm{~s}$, since majority rule? Is this like the UK, with Liebenberg's good data and estimates coming too late to influence policy? Is the USA really the only country rich enough to afford sufficient timely research to avoid stagnation in TFP growth?

\section{Figure 6: South African Public Sector Agricultural R\&D}

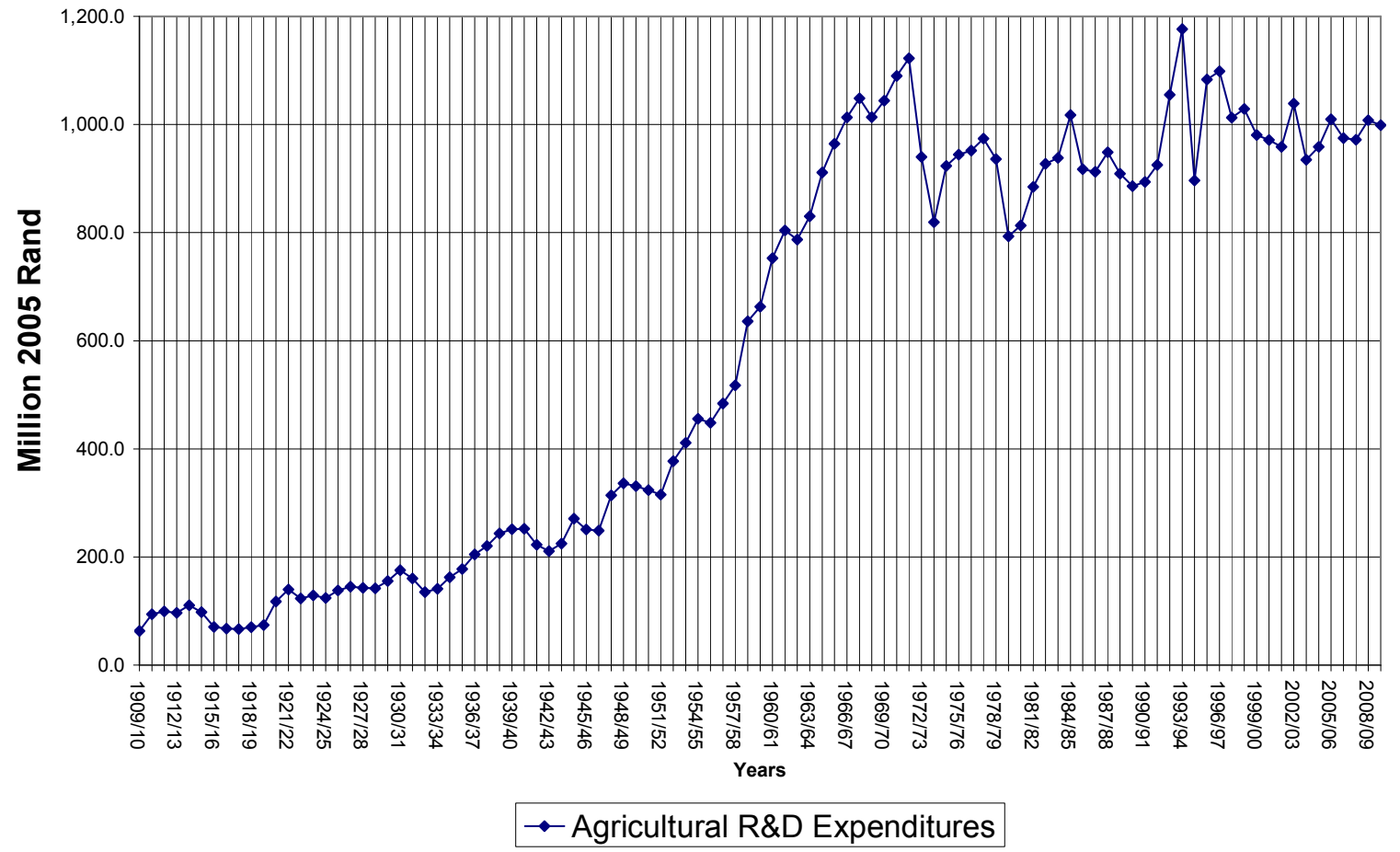

Source: Liebenberg (2010). 
Figure 7: South African Output, Input and TFP Indices: TFP Growth Ceases at About 1989

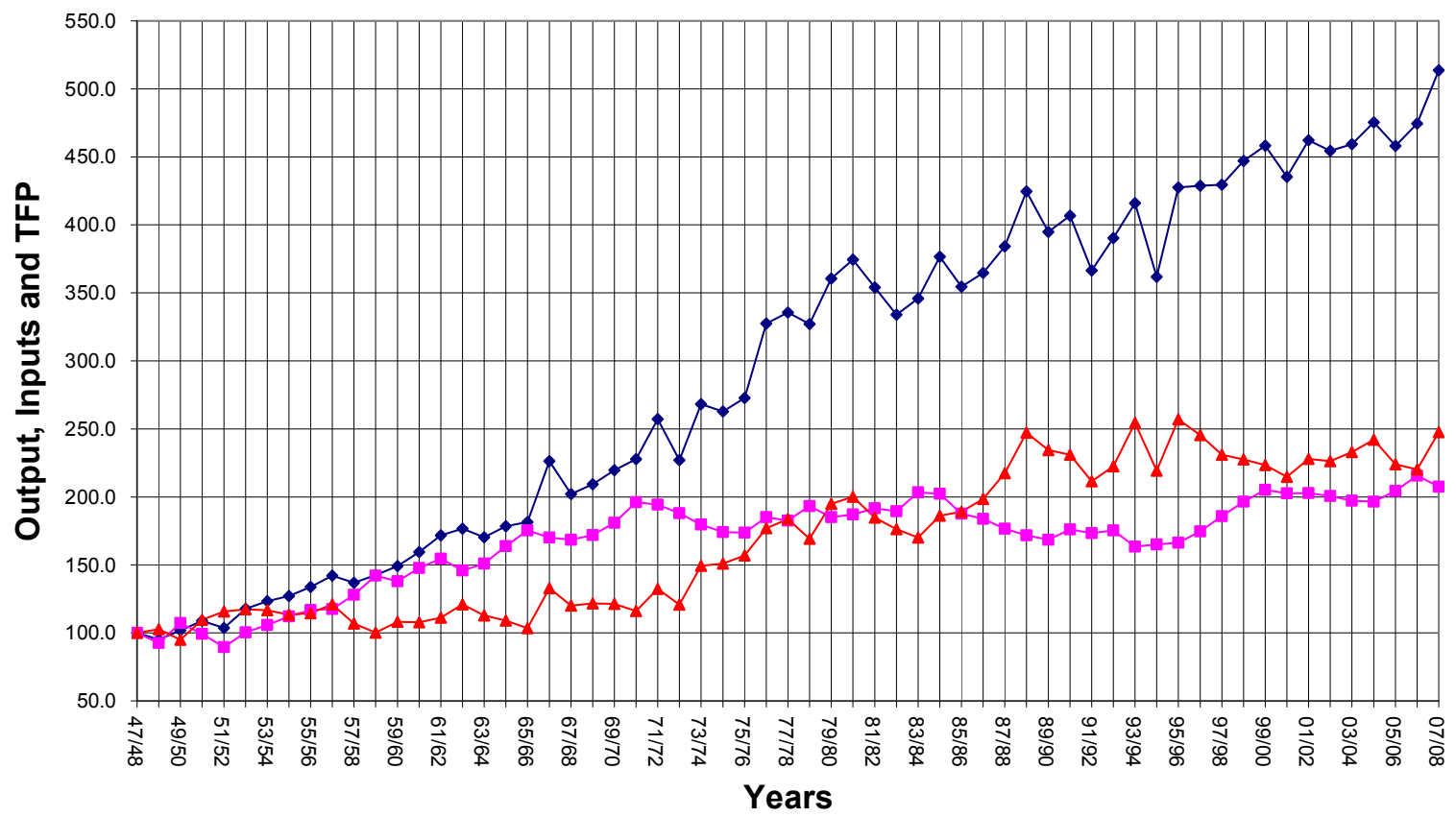

$\rightarrow$ Output - - Input $\_$TFP

Source: Liebenberg (2010)

\section{CONCLUSIONS}

Do what you can, with what you've got, where you are. Abraham Lincoln

At a basic level this paper explains why refutation is difficult in economics, but we have moved towards understanding the data, determining its properties and seeing what it can tell us, rather than simply imposing restrictive theory on it. Poor results now may cause further investigation of alternative models, rather than tampering with the data until it fits. This is a change in emphasis rather than a radical departure from bad old ways. There has been a serious movement towards using econometric tests to determine the correct model and to avoid imposing arbitrary restrictions on the data by using inadequate models. None of this is startling, but it does represent solid progress, even if we are testing the data, the model and the econometric specification rather than the underlying neoclassical theory. So does the tendency to think more about appropriate levels of aggregation and to test the data to see if it can be pooled. The review of progress in production and technology shows that our SRP has been progressive. My own view is that applied economics is not science, but an art form based on choosing modelling and estimation techniques that best match the data, in the sense of exploiting its strengths and minimising its weaknesses.

But we are undoubtedly a policy science and this must affect our behaviour. We can try to be scientific, but we need to influence policy in a way that will ensure the outcome that is most socially desirable. The US profession has always had a PAP and this paper shows the benefits that have resulted from it. The UK profession did not take a political stance and this, combined with the lack of data and policy relevant advice, has been costly in terms of lost productivity. As far as I can see with 20/20 hindsight, we earn our keep by providing information and should try to defend important agricultural budgets better. South Africa may not be able to compete with 
the US in this regard, but I do think we have done much better here than in the UK. Even so, the results show that TFP growth seems to have stalled.

The US example shows that getting the institutions right, collaborating across disciplines and ensuring articulation between the national and state agriculture departments and the universities are all important. The system is held back to the pace of the weakest link. Those of you who work here may not realise it, but you have the privilege of practicing your trade in the world's social science laboratory. It is also one of the few counties in the world where your findings need to be correct as the policy makers do listen and implement our recommendations. By contrast, in most developed countries the politicians take no notice and in most developing countries policies are not implemented due to lack of funds. There is also a lot at stake. If South Africa does not succeed in transforming its agricultural system and providing some leadership for the rest of SADC, progress in Southern Africa will be very slow.

My personal view is that we have done rather well since majority rule in terms of the progress we have made within the confines of our subject. But if we view our objective as poverty reduction, we are failing miserably, in South Africa and indeed in most of SSA. The FAO view I picked up was that it should be possible to produce enough food to feed the world in 2050, but entitlements will be the problem. Few can see how output and incomes in rural SSA can be increased to adequate levels. That is the biggest global challenge for our subject and we can show that the impact of agricultural growth on poverty reduction in both urban and rural areas is unrivalled. This will ensure that we really are a crucial and relevant disciple for a long time to come, both domestically and internationally. At some point the government has to face the fact that not enough is being done to help the rural poor. If we can play a role in poverty alleviation and stabilising population movements there may be a case for funding agriculture rather than spending all the money on housing migrants from the Eastern Cape and the rest of Africa.

In conclusion, one prediction I will make is that the days of falling farm prices and the declining importance of agriculture are over. Agriculture has become a part of the huge and growing energy industry (Piesse and Thirtle, 2010). Adjusting to this monumental change, combined with attacking climate change and increasing environmental and resource problems should keep us busy for the next fifty years.

\section{REFERENCES}

Alston, J.M., P.G. Pardey and J.M. Beddow (2010) Global Patterns of Crop Yields and Other Partial Productivity Measures and Prices, Chapter 3 in J.M. Alston, B. Babcock and P.G. Pardey, eds. The Shifting Patterns of Agricultural Production and Productivity Worldwide, CARD-MATRIC Electronic Book, Ames: Iowa State University

Barton G T and Cooper M R (1948) Relation of Agricultural Production to Inputs, Review of Economics and Statistics, 30, 117-126

Blaug M (1980) The Methodology of Economics: or How Economists Explain, Cambridge University Press

Boland (1977) Testability in Economic Science, South African Journal of Economics, 45, 93-105 
Caldwell B (1982) Beyond Positivism: Economic Methodology in the Twentieth Century, Allen and Unwin, London

Christensen L R, Jorgensen D W, and Lau L (1973) Transcendental Logarithmic Production Frontiers, Review of Economics and Statistics, 55, 28-45

Evenson R (2000) Productivity and Agricultural Growth in the Second Half of the 20th Century: Study of Food and Agriculture, FAO, Rome.

Evenson R, Waggoner P and Ruttan V (1979), Economic Benefits from Research: An Example from Agriculture, Science, 205, 1101-1107

Fox K (1986) Agricultural Economists as World Leaders in Applied Econometrics, American Journal of Agricultural Economics, 68, 381-6

Goldberger A S (1974) Unobservable Variables in Econometrics, in P Zarembka (ed), Frontiers in Econometrics, Academic Press, New York

Grigg D (1989), English Agriculture: An Historical Perspective, Blackwell, Oxford

Griliches Z (1958) Research Costs and Social Returns: Hybrid Corn and Related Innovations, Journal of Political Economy, 66, 419-31

Griliches Z (1964) Research Expenditures, Education and the Aggregate Agricultural Production Function, American Economic Review, 54, 961-74

Griliches Z (1994) Productivity, R\&D and the Data Constraint, American Economic Review, 84, 123

Hayami Y and Ruttan V (1985), Agricultural Development: An International Perspective, revised edition, Baltimore: Johns Hopkins University Press

Heady and Dillon (1962) Agricultural Production Functions, Iowa State University Press, Ames, Iowa

Heisey P Wang S L and Fuglie K (2011) Public Agricultural Research Spending and Future Agricultural Productivity Growth: Scenarios for 2010 to 2050, Economic Brief Number 17, July, ERS, USDA, Washington DC

Holderness B (1985), British Agriculture since 1945, Manchester University Press, Manchester Hoselitz B F (1960) Theories of Economic Growth, B F Hoselitz (ed), The Free Press, New York

Huffman W and Evenson R (1992), Contribution of Public and Private Science and Technology to US Agricultural Productivity, American Journal of Agricultural Economics $74: 3,751-6$

Koopmans T (1952) Measurement Without Theory, Review of Economic Statistics, 29, 161-72

Kuhn T (1970) The Structure of Scientific Revolutions, $2^{\text {nd }}$ edition, University of Chicago Press 
Lakatos, I (1970) Falsification and the Methodology of Scientific Research Programmes, in Lakatos I \& Musgrave, A (eds.) (1970), Criticism and the Growth of Knowledge, Cambridge (Cambridge University Press).

Liebenberg F (2010) South African Agricultural Production and Investment Patterns, Farm Foundation-ERS Conference on Global Agricultural Productivity May 11-12, 2010; Waugh Conference Center, ERS, Washington DC.

Lipton M with Longhurst R (1989) New Seeds and Poor People, Unwin Hyman, London

Nerlove M (1958) The Dynamics of Supply: Estimation of Farmer's Response to Price, Johns Hopkins Press, Baltimore

Nelson R and Winter S G (1982) An Evolutionary Theory of Economic Change, The Belknap Press, Cambridge, Mass

Nin Pratt A and Yu B (2008), An Updated Look at the Recovery of Agricultural Productivity in Sub-Saharan Africa, IFPRI Discussion Paper 00787

Nordhaus W D (2002) The Progress of Computing, Working Paper from http://www.j-bradforddelong.net/movable_type/refs/Safari_Scrapbook3/prog_030402_all.pdf

Pardey P and Craig B (1989), Causal Relationships between Public Sector Agricultural Research Expenditures and Output, American Journal of Agricultural Economics, 71:1, 9-19

Piesse J and Thirtle C (2010) Agricultural investment, extension, research and development, Philosophical Transactions of the Royal Society, Series B, 365, 3035-47.

Popper K (1963) The Logic of Scientific Discovery, Routledge, London

Prigogine I and Stengers I (1985) Order Out of Chaos: Man's New Dialogue with Nature, Fontana, London

Rosenberg N (1982) Inside the Black Box: Technology and Economics, Cambridge University Press, Cambridge

Schimmelpfennig D and Thirtle C (1999), Research Spillovers Between the European Community and the United States, Contemporary Economic Policy, 19:4, 457-68

Schultz T W (1953) Economic Organisation of Agriculture, McGraw Hill, New York

Solow R M (1957) Technical Change and the Aggregate Production Function, Review of Economics and Statistics, 39, 312-20

Tangri O P (1966) Omissions in the Law of Variable Proportions, American Economic Review, 56, 484-93

Thirtle, C. and Bottomley, P. (1988), Is Publicly Funded Agricultural Research Excessive? Journal of Agricultural Economics, 39, 99-111 
Thirtle, C. and Bottomley, P. (1992), Total Factor Productivity in UK Agriculture, 1967-90, Journal of Agricultural Economics, 43, 381-400

Thirtle, C, Lin, L and Piesse, J (2002), The Impact of Research Led Agricultural Productivity Growth on Poverty Reduction in Africa, Asia and Latin America, World Development, 31, 1959-75

Thirtle, C., Bottomley, P., Palladino, P. and Shimmelpfennig, D.S. (1998), The Rise and Fall of Public Sector Plant Breeding in the UK: A Recursive Model of Basic and Applied Research, and Diffusion, Agricultural Economics, 19, 127-43.

Thirtle, C, Lin, L, Holding, J and Jenkins, L (2004), Explaining the Decline in UK Agricultural Productivity Growth, Journal of Agricultural Economics, 55, 343-366

Thirtle C, Palladino P and Piesse J (1997), On the Organisation of Agricultural Research in Great Britain, 1945-94: A Quantitative Description and Appraisal of Recent Reforms, Research Policy, 26, 557-76

Thirtle C, Piesse J and Schimmelpfennig D (2008), Modelling the Length and Shape of the R\&D Lag: An Application to UK Agricultural Productivity, Agricultural Economics, 39, 73-85

Thirtle, C., Sartorius von Bach, H. and van Zyl, J. (1993), Total Factor Productivity in South African Agriculture, 1947-91, Development Southern Africa, 10, 301-18

Tintner G. 1944. A note on the derivation of production functions from farm records.

Econometrica, 1, 26-34

Tintner G (1952) Econometrics, Wiley, New York

Townsend R F (1997) Econometric Methodology I: The Role of Theory and Observation in Agricultural Economics Research, Agrekon, 36, 325-47

Townsend R F (1998) Econometric Methodology II: Strengthening Time Series Analysis Agrekon, 37, 83-99

Townsend, R. and Thirtle, C. (2001), Is Livestock Research Unproductive? Separating Health Maintenance from Improvement Research, Agricultural Economics, 25, 177-89.

Wise, W.S. (1986) The Calculation of Rates of Return on Agricultural Research from Production Functions, Journal of Agricultural Economics, 37(2). 